\title{
Stygiomysis aemete n. sp., a new subterranean mysid (Crustacea, Mysidacea, Stygiomysidae) from the Dominican Republic, Hispaniola
}

\author{
Amsterdam Expeditions to the West Indian Islands, Report 72*
}

\author{
H.P. Wagner \\ Institute of Taxonomic Zoology (Zoölogisch Museum), P.O. Box 4766, 1009 AT Amsterdam, The \\ Netherlands
}

Keywords: Stygofauna, Mysidacea, Stygiomysidae, Stygiomysis, taxonomy, biogeography, Hispaniola

\begin{abstract}
During the Amsterdam Expedition to the Dominican Republic a new Stygiomysis species, $S$. aemete, was captured in a well about $5 \mathrm{~km}$ east of the Haitian border in the Pedernales Province. Its relation to the other Caribbean Stygiomysis species as well as the biogeography of the genus is discussed.
\end{abstract}

\section{Resumen}

Durante la "Expedición Amsterdam a la República Dominicana" se encontró una nueva especie de Stygiomysis, S. aemete, en un pozo aproximadamente $5 \mathrm{~km}$ al este de la frontera de Haití en la Provincia de Pedernales. Se trata la relación con los otros especies de Stygiomysis del Caribe, así como la biogeografia del género.

\section{Introduction}

During the Amsterdam West Indian Expedition to the Dominican Republic (Hispaniola) in 19871988, a large stygobiont mysid was captured. It represents a new species of Stygiomysis Caroli, 1937, and will be described below.

This is the fifth species of Stygiomysis described and the fourth from the Caribbean region. Previously described species are: $S$. hydruntina Caroli, 1937 (Salentine Peninsula, Italy); S. holthuisi (Gordon, 1958) (St. Martin, Anguilla, Puerto Rico, and
Grand Bahama Island) (see also Gordon, 1960; Bowman, 1976; Botosaneanu, 1980; Bowman et al., 1984); S. major Bowman, 1976 (Jamaica); and S. clarkei Bowman, Iliffe \& Yager, 1984 (Middle Caicos Island and Providenciales Island). Furthermore, there are three other undescribed species known, one from the Salentine Peninsula, Italy (Stygiomysis sp., Pesce, 1976), one from Quintana Roo, Mexico (Bowman, in litt.), and one from Florida, U.S.A. (Bowman, in litt.).

\section{Systematics}

Stygiomysis aemete n. sp. (Figs. 1-6)

Material and locality. - Dominican Republic: 1 \% holotype, sta. 87/615, Prov. de Pedernales, ca. $2.8 \mathrm{~km}$ E. of Pedernales, $1650 \mathrm{~m} \mathrm{~N}$.E. of road, $18^{\circ} 02^{\prime} 05^{\prime \prime} \mathrm{N} 71^{\circ} 42^{\prime} 47^{\prime \prime} \mathrm{W}$, $+5 \mathrm{~m}$ mean sea level; in a well, half covered by wood, opening $0.8 \times 1.5 \mathrm{~m}$; temp. $27.1^{\circ} \mathrm{C}, 95 \% \mathrm{O}_{2}$, conductivity $736 \mu \mathrm{S} / \mathrm{cm}$; collected with Cvetkov-net; water table + depth $=1.5+0.5 \mathrm{~m}$; 19 Nov. 1987; leg. H.P. Wagner \& N.W. Broodbakker. Accompanying fauna: drowned Insecta (mainly ants). The holotype is preserved in the Zoölogisch Museum Amsterdam under coll. no. Schi. 150.193 (a, body; b, mouthparts; on slide). The specimen is coloured by black chlorazol B cuticular staining.

Description. - Body vermiform (Fig. 1), unpigmented, $15.46 \mathrm{~mm}$ long (measured from rostrum to posterior end of telson). Rudimentary eyestalks present, without visual elements (Fig. 2d).

* Report 71 is published in Bull. Inst. r. Sci. nat. Belg., Entomologie 61 (1991). 


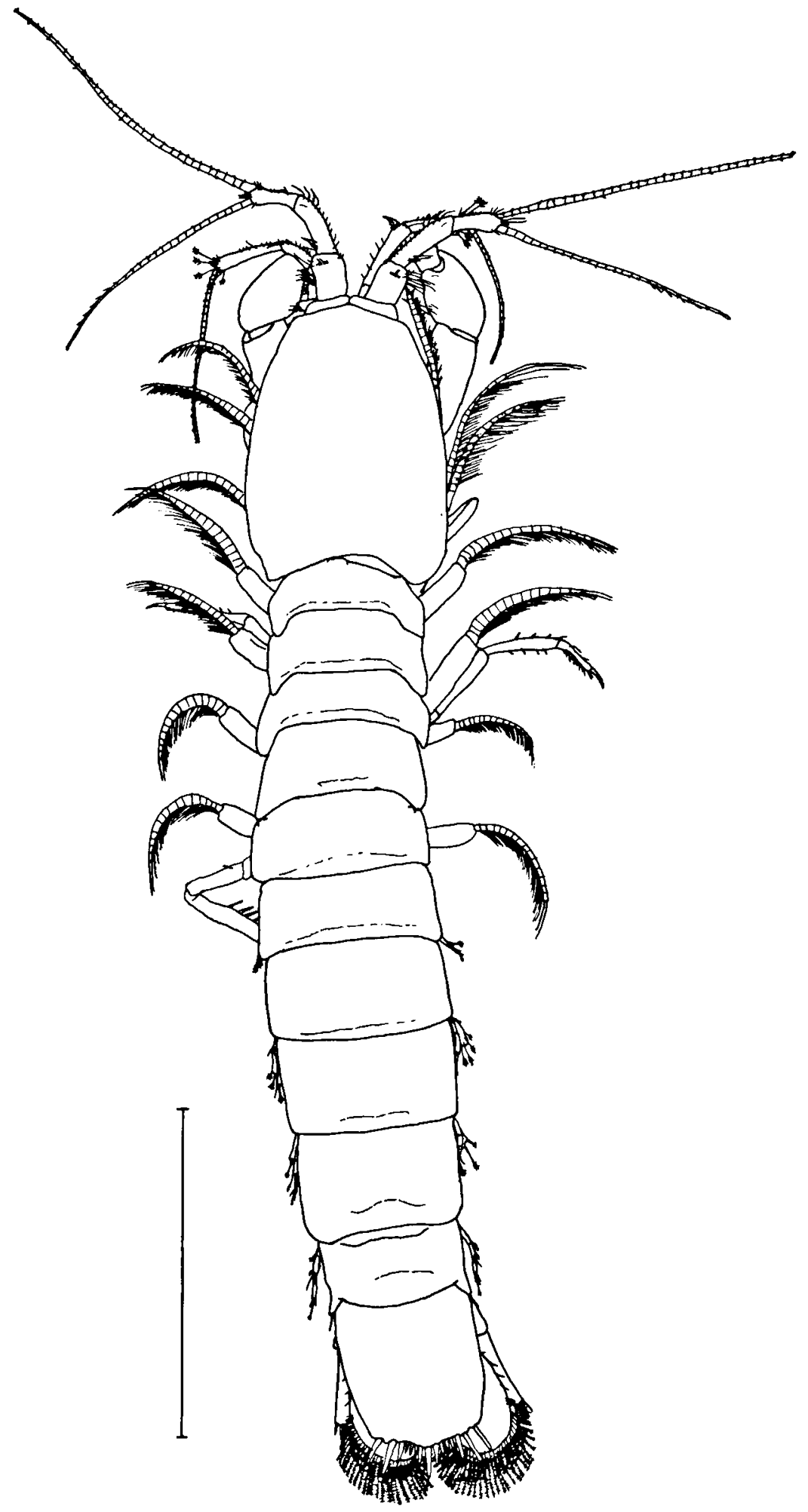

Fig. 1. Stygiomysis aemete n. sp., $Q$ (holotype), habitus in dorsal view (scale $=5 \mathrm{~mm}$ ). 


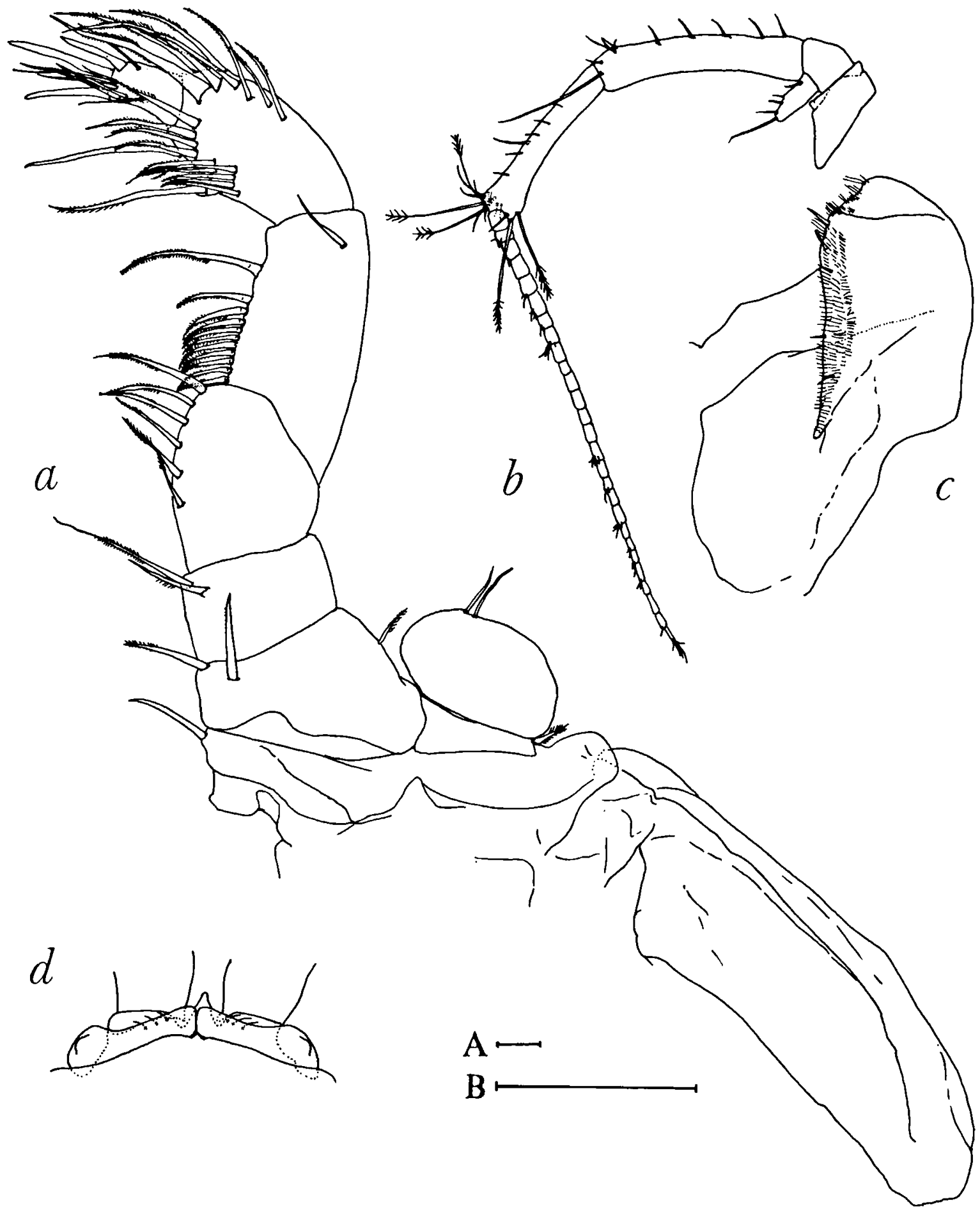

Fig. 2. Stygiomysis aemete n. sp., \& (holotype): a, right maxilliped; b, left antenna; c, labium (half); d, rudimentary eyestalks and rostrum ( $a$ and $c$ : scale $A=0.1 \mathrm{~mm} ; b$ and $\mathrm{d}$ : scale $B=1 \mathrm{~mm}$ ). 


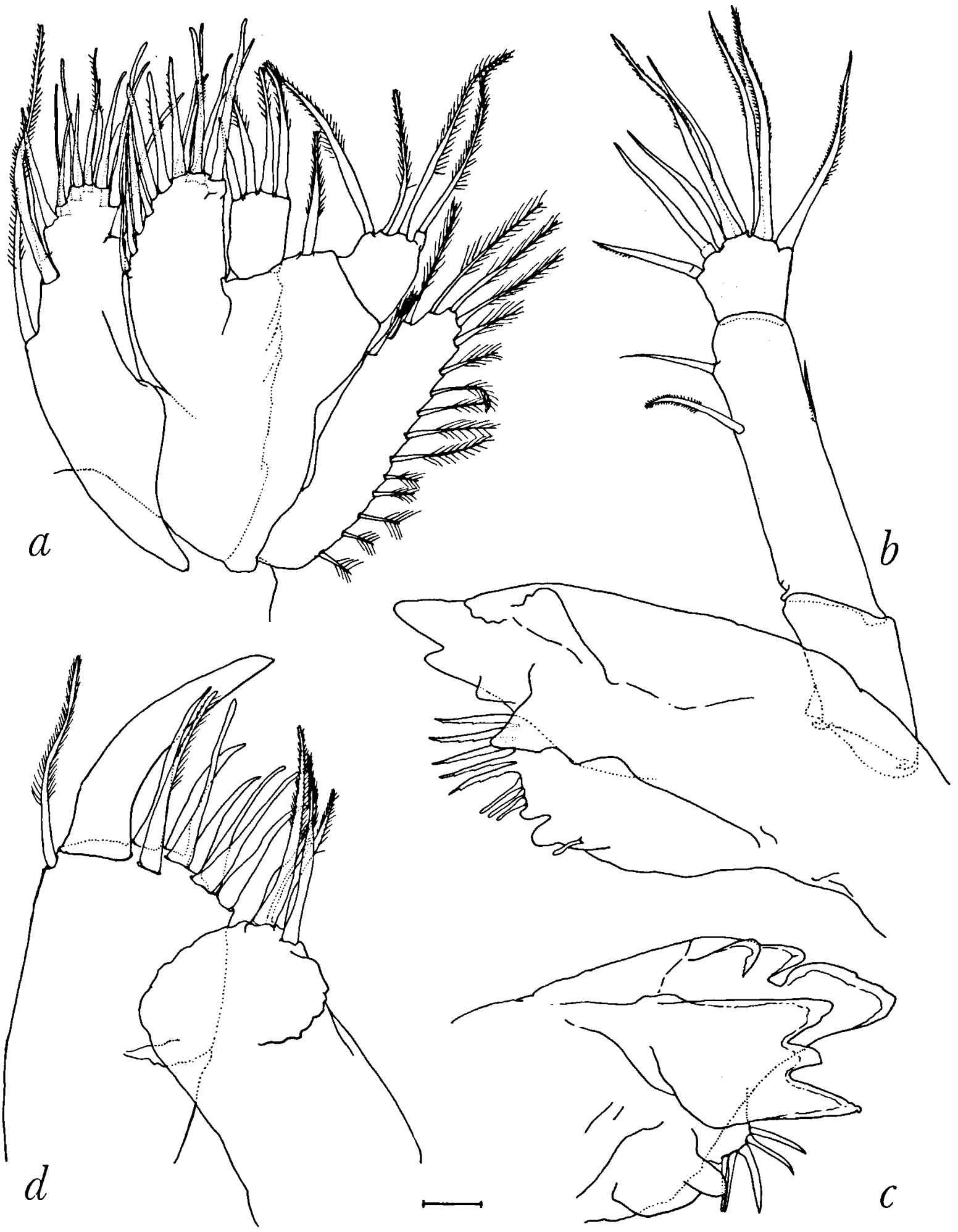

Fig. 3. Stygiomysis aemete n. sp., ९ (holotype): a, right maxilla 2; b, right mandible; c, gnathal surface of left mandible; d, right maxilla 1 (scale $=0.1 \mathrm{~mm})$. 
Antennula (Fig. 4c), peduncle length approximately one third of carapace; outer flagellum shorter than inner, 25-segmented, segments 18-23 with an aesthetasc each; inner flagellum 33-segmented.

Antenna (Fig. 2b) with a scale armed with 1 apical and 4 medial setae; flagellum distinctly shorter than flagella of antennula, 27-segmented.

Labrum (Fig. 4d) distinctly broader than long, triangular.

Mandible with 3-segmented palp; second segment with 1 plumose and 2 naked setae; third segment with 5 plumose and 3 naked setae. Left mandible (Fig. 3c) with 3-cuspidate incisor and lacinia; spine row with 5 spines; molar process carrying 1 blunt tubercle. Right mandible (Fig. 3b) with 4-cuspidate incisor plus accessory cusp; spine row with 5 (fixed) spines; molar process carrying 1 blunt tubercle and 4 blunt setae.

Labium (Fig. 2c) finely setose, with 5 stronger setae.

Maxilla 1 (Fig. 3d), inner lobe with 4 plumose setae of irregular size; outer lobe with strong spine flanked by a pair of unequally plumose slender setae and medially by 3 pointed and 4 blunt slender spines.

Maxilla 2 (Fig. 3a), proximal endite with 10 long setae ( 3 being plumose) and 4 shorter setae; distal endite divided into lobes with 12 and 4 marginal spines; proximal and distal segments of endopodite with 1 and 4 plumose setae, respectively; exopodite with 17 marginal plumose setae, 4 of them on medial margin.

Maxilliped (Fig. 2a) densely setose (especially propodus); propodus and dactylus relatively short compared to $S$. holthuisi or S. major.

Pereiopod 1 (Fig. 4a), main unguis longer than body of dactylus, accessory claw 0.55 times length of main unguis; propodus armed with 4 large spines and 8 setae; exopodal flagellum 15 -segmented, each segment with a pair of long setae, except for last segment which has 2 pairs of long setae.

Pereiopod 2 (Fig. 4b), main unguis almost twice length of dactylus, accessory claws about $\mathbf{0 . 4 3}$ and 0.55 times length of main unguis; propodus with 3 large and 6 smaller spines; exopodal flagellum 16-segmented, each segment with a pair of long setae, except for last segment which has 2 pairs of long setae.
Pereiopod 3 (Fig. 5a), main unguis about 0.17 of length of dactylus; propodus with 4 spines and 4 setae on ventral margin, and 7 setae on dorsal margin; dactylus densely setose; exopodal flagellum 15-segmented, each segment with a pair of long setae, except for last segment which has 2 pairs of long setae.

Pereiopods 4 to 7 (Figs. 5b-e) with an increasing number of spines; an elongate serrate seta accessory to the unguis; exopodal flagella 15 -segmented, each segment with pair of long setae, except for last segment which has 2 pairs of long setae.

Pleopods (Figs. 6a-e) with 1-segmented endopodites and 3-segmented exopodites; basis of pleopods 1 and 2 free from pleonite; basis of pleopods 3 to 5 fused with pleonites; patterns of setation as illustrated.

Protopodal process of uropod (Fig. 6g) with 1 subapical and 3 lateral setae; 5 subapical to apical spines separated from 2 medial spines by 9 spinules. Endopodite and exopodite ornamented with numerous plumose setae (Fig. 6f).

Telson (Fig. 6h) longer than wide; posterior margin with a central group of 3 rather long spines of which middle spine longest, flanked by 3 short subequal spines and lateral group of 3 long spines with inner spine shortest.

Etymology. - The specific (Anglo-Saxon) epithet means "ant" as the animal was captured while swallowing an ant that was drowned in the well.

\section{Relationships}

The new species is distinct from $S$. holthuisi by its larger size (1.5 times larger), a larger number of flagellum articles of antennulae and antennae, the apically much more setose maxillipeds, the slightly more setose pereiopods and pleopods, and the lower number of medial spines anteriad of the spinules of the protopodal process of the uropod.

The new species most closely resembles $S$. major in size (the latter can reach somewhat larger proportions) and body shape, but is distinguished by a lower number of flagellum segments of antennulae and antennae, slightly less setose pereiopods and 


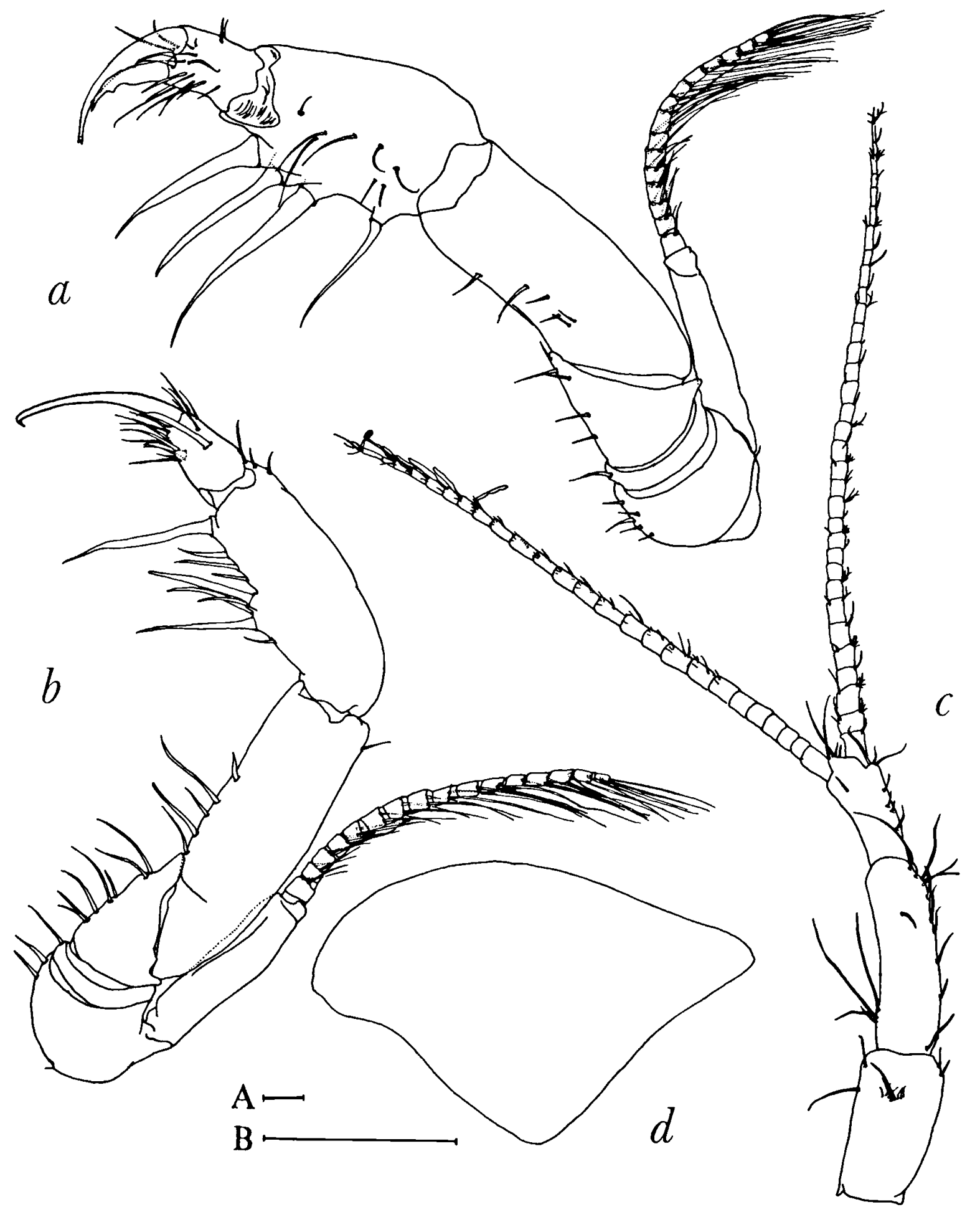

Fig. 4. Stygiomysis aemete n. sp., \& (holotype): a, left pereiopod 1; b, left pereiopod 2; c, left antennula; d, labrum (a-c: scale B = $1 \mathrm{~mm}$; d: scale $A=0.1 \mathrm{~mm}$ ). 


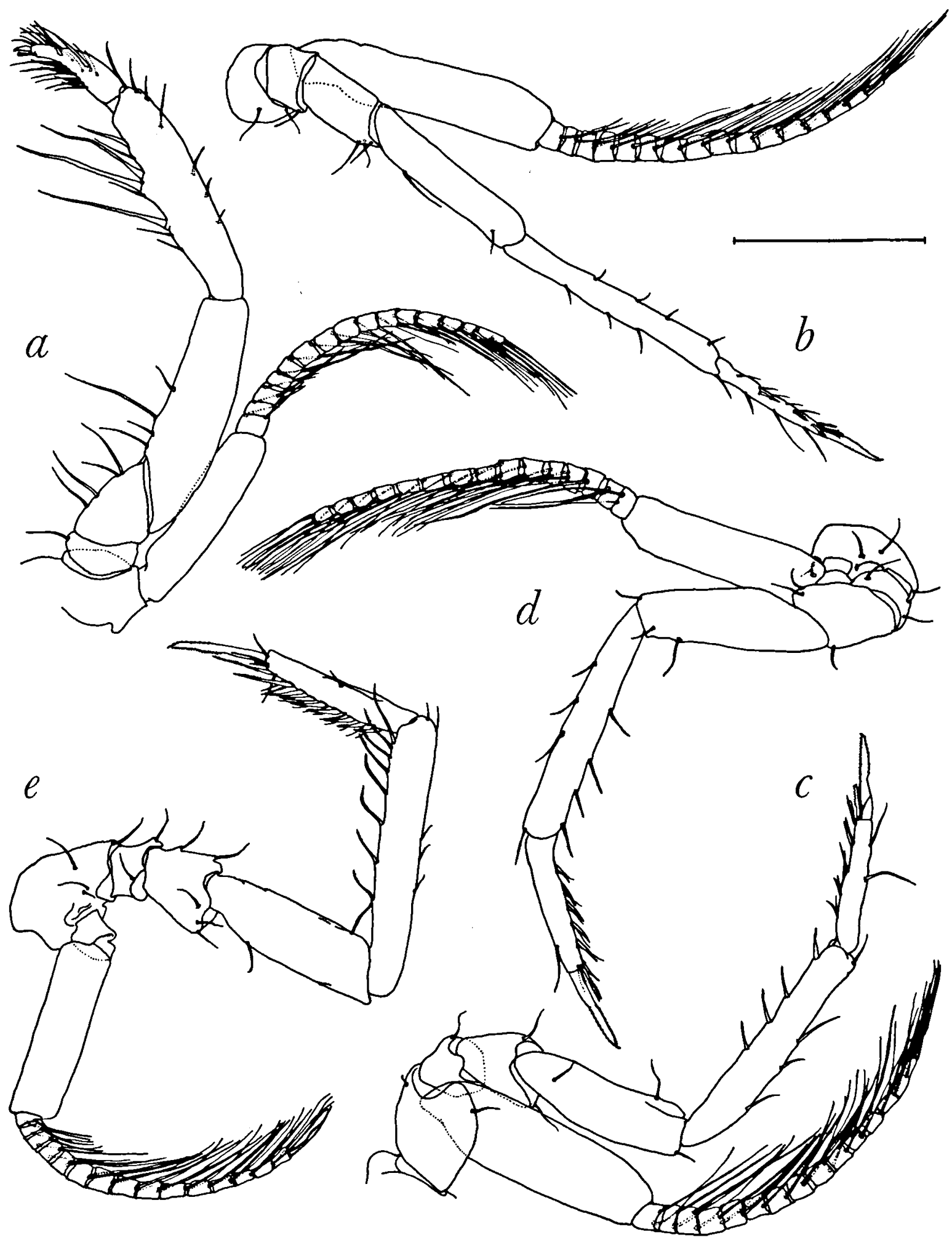

Fig. 5. Stygiomysis aemete n. sp., $Q$ (holotype): a, left pereiopod 3; b, right pereiopod 4; c, left pereiopod 5; d, right pereiopod 6; e, right pereiopod 7 (scale $=0.1 \mathrm{~mm})$. 

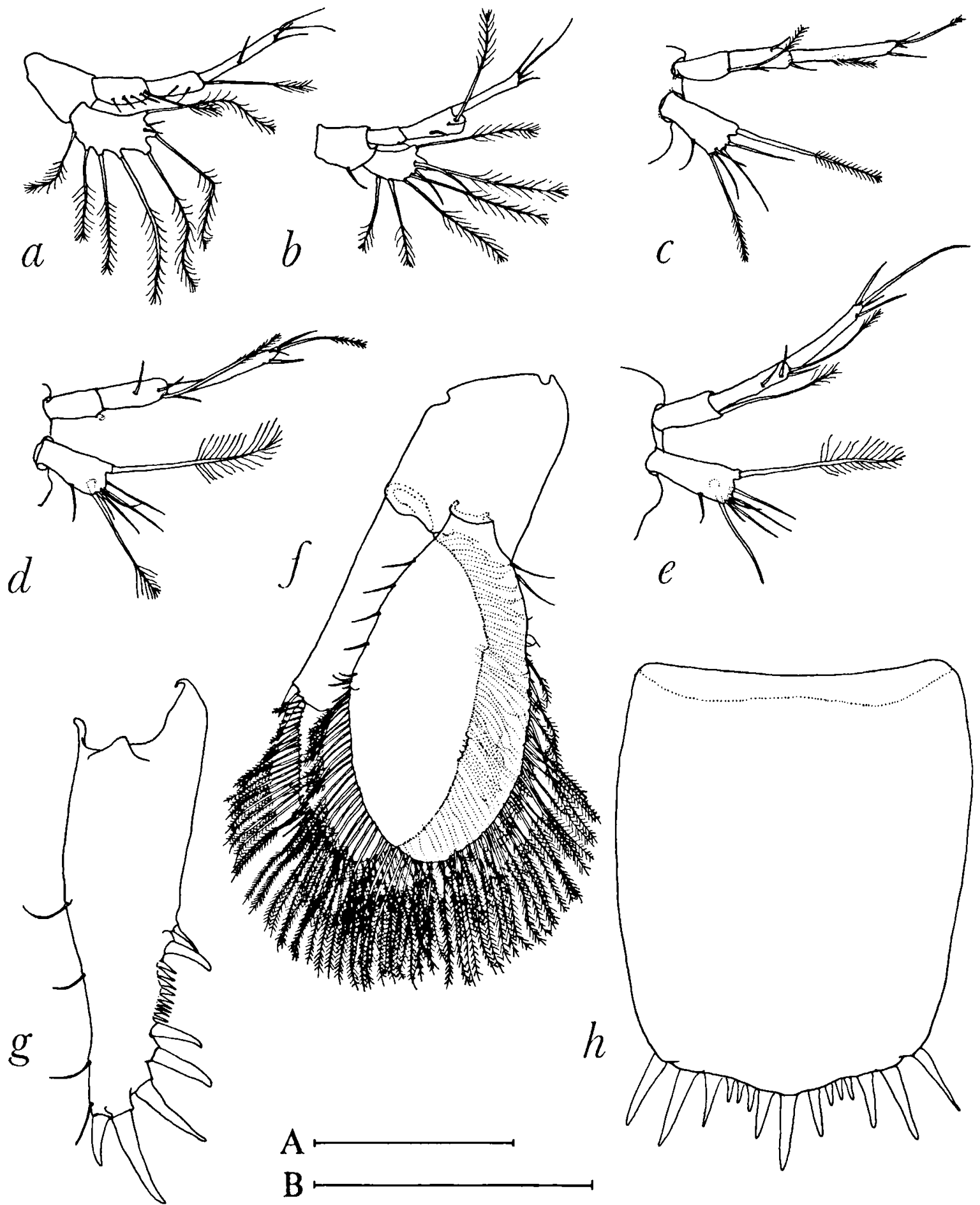

Fig. 6. Stygiomysis aemete n. sp., \& (holotype): a, left pleopod 1; b, left pleopod 2; c, left pleopod 3; d, left pleopod 4; e, left pleopod 5; f, endopodite and exopodite of left uropod; $g$, protopodal process of left uropod; $h$, telson (a-e: scale B = $1 \mathrm{~mm} ; \mathrm{g}-\mathrm{h}$ : scale A $=1 \mathrm{~mm})$. 
pleopods, fewer medial spines, but distinctly more spinules, on the protopodal process of the uropod.

The new species is clearly distinct from $S$. clarkei by its much larger size ( 2.5 times larger), the outer flagellum of the antennula being shorter than the inner (the reverse in $S$. clarkei), a larger number of articles in flagellum of antennulae and antennae, the apically much more setose maxillipeds, and the larger number of setae on maxilla 2, pereiopods, and pleopods. Furthermore, the protopodal process of the uropod is more elongate and the telson is somewhat wider than long.

\section{Biogeography}

The remarkable distribution of the genus Stygiomysis, with two species in Italy and six in the northern and western part of the Caribbean region and surrounding area, undoubtedly points to a Tethyan origin of this group. However, some reserve must be taken into account when interpreting the distribution patterns at the specific level. Thus far $S$. hydruntina and $S$. sp. from Italy, and the Caribbean species $S$. major and $S$. aemete $\mathrm{n}$. sp., are known from one or just a few specimens from a limited area only. All inhabit freshwater habitats. Only $S$. holthuisi and $S$. clarkei are known from more than one locality - actually, more than one island -, where they are known from anchihaline habitats. A similar situation can be observed in the Thermosbaenacea, where the anchihaline Halosbaena acanthura Stock, 1976, is found on Islas de Aves (Venezuela), Curaçao (Netherlands Antilles), Bonaire (N.A.), San Andros Island (Colombia), Cuba, and Jamaica (Wagner, unpubl. data). On the contrary, on those islands where representatives of the thermosbaenacean family Monodellidae are found as inhabitants of fresh water, only endemic species are concerned. It seems therefore most probable that a more recent invasion of the groundwater by $S$. holthuisi and $S$. clarkei is responsible for their larger area of distribution, or, that migration through open sea is possible.

Dr. T.E. Bowman informed me of the existence of two other (new) species of Stygiomysis, one from a cave in Quintana Roo (Mexico) and the other from southern Florida, the latter having small eyes
(Bowman, in litt. 17-XI-1988). Considering the small or reduced eyes, the hypothesis of a rather recent invasion of the groundwater is favoured over the one suggesting present migration through open sea. In the case of $S$. holthuisi the time passed since the invasion is too short to permit morphological changes on the specific level, as exemplified by Bowman (1976), Bowman et al. (1984), and Botosaneanu (1980), who consider the existing (slight) differences between the various populations of this species not sufficient to recognize distinct taxa.

\section{Acknowledgements}

I am most indebted to Dr. Thomas E. Bowman (Smithsonian Institution, Washington), and Prof. Dr. Jan H. Stock (Institute of Taxonomic Zoology, Amsterdam) for their valuable comments on the manuscript. My wife Elsa is acknowledged for her support and for correcting the first draft of this paper. The fieldwork on which the present study is based has been financed by a grant received from the Foundation of Fundamental Biological Research (BION), which is subsidized by the Netherlands Organization of Scientific Research (NWO).

\section{References}

Botosaneanu, L., 1980. Stygiomysis holthuisi found on Anguilla (Crustacea: Mysidacea). Stud. Fauna Curaçao, 61(190): 128132.

Bowman, Th.E., 1976. Stygiomysis major, a new troglobitic mysid from Jamaica, and extension of the range of S. holthuisi to Puerto Rico (Crustacea: Mysidacea: Stygiomysidae). Int. J. Speleol., 8: 365-373.

Bowman, Th.E., Th. M. Iliffe \& J. Yager, 1984. New records of the troglobitic mysid genus Stygiomysis: S. clarkei, new species, from the Caicos Islands, and S. holthuisi (Gordon) from Grand Bahama Island (Crustacea: Mysidacea). Proc. biol. Soc. Wash., 97(3): 637-644.

Caroli, E., 1937. Stygiomysis hydruntina n. g., n. sp., misidaceo cavernicolo di Terra d'Otranto, rappresentante di una nuova famiglia. Boll. Zool., Torino, 8(5-6): 219-227.

Gordon, 1., 1958. A new subterranean crustacean from the West Indies. Nature, 181: 1552-1553.

Gordon, I., 1960. On a Stygiomysis from the West Indies, with a note on Spelaeogriphus (Crustacea, Peracarida). Bull. Br. Mus. (Nat. Hist.), Zool., 6(5): 283-324, pls. 3-4.

Pesce, G.L., 1976. On a Stygiomysis (Crustacea, Mysidacea) from the southern Italy. Boll. Mus. civ. Stor. nat. Verona, 2: 439-443.

Received: 25 February 1992

Revised: 16 June 1992 